\title{
Leadership for health. How can we ensure that the values and principles of public health become central to health and social policy?
}

\author{
Maureen Dalziel
}

After three years of the present British government, it is becoming clear that it is committed to raising clinical standards and modernising the National Health Service. ${ }^{1-3}$ In addition, the NHS white paper ${ }^{2}$ seeks to refocus health services to take on board a public health agenda that aims to reduce ill health and health inequalities for the whole population. Acknowledging that the NHS alone cannot achieve this agenda, the paper puts considerable emphasis on inter-agency collaboration and joint working. The duty of achieving this partnership will be placed on the key stakeholders.

These themes of collaboration are reiterated in the public health white paper, ${ }^{1}$ which proposes "national contracts for health" in the priority areas of heart disease and stroke, accidents, cancer and mental health. The paper also promises "a concerted and co-ordinated drive against poor health", and similar commitments are given in other government documents.

For its part, the government has appointed a minister for public health and a ministerial cabinet committee drawn from 12 departments, and has given a commitment to assess the impact of relevant policies on public health. Health authorities will lead local alliances to develop health improvement programmes. The programmes will address national and local priorities and will shape local health care provision. The primary role of health authorities is changing from one of commissioning, which will largely be devolved to primary care groups, to that of strategic leadership in improving the health of the population. Public health specialists, both medical and nonmedical, have a crucial part to play in this era, as their primary concern is with the health of the population. Opportunities now exist to ensure that the government's policy agenda is harnessed to improve health and health care, and to direct the creation and implementation of future health policy.

There is a danger, however, that the management of financial resources and waiting lists will continue to dominate the day to day agenda of the NHS.

How can the principles of health improvement become truly influential in this agenda, not only for the health service but also across government? Is it possible for the principles, values and beliefs of public health to become more visible and persuasive with the public and thus politicians?

To answer some of these questions the role of public health specialists, across North London and the counties of Hertfordshire and Essex, was reviewed during 1997 by the National Health Service Executive, North Thames Region. ${ }^{4}$ The review demonstrated that a broad range of stakeholders, both inside and outside the NHS, considered the principles and practice of the public health specialist to be central to the health decision making process. There was consensus too that these specialists should focus on health issues where resolution lies in health and social policy changes.

An important finding was that public health specialists must be technically competent in the surveillance, analysis, synthesis and evaluation of health and health care issues. One of the greatest skills of the public health specialist was considered to be the ability to develop and facilitate extensive networks, both inside and outside the NHS.

The networks were seen as an appropriate mechanism for tackling a variety of issues to the benefit of local health organisations and the populations they serve. These networking skills will be crucial in the future when identifying and building alliances across the health spectrum, and when managing the interface between the constituent bodies.

The role and purpose of the public health specialist, although understood and valued by those who work alongside them, was invisible to those that had little contact with them on a day to day basis. The public health specialist was therefore considered to have little influence.

If public health interests are to drive future health policy, then leaders and practitioners will be needed that are not only technically competent but also able to influence and persuade at the highest levels.

Public health specialists are well placed to do this. Public health doctors have a seat on the board of all health authorities and hold senior positions within the National Health Service Executive. Other public health specialists have positions of influence throughout the health and social care sector including the NHS, universities, local authority and voluntary organisations, and as shown by the North Thames review, ${ }^{4}$ are considered to have good cross organisational networks. Without the subtle skills needed to achieve change in a less than receptive environment, its practitioners will fail, however technically competent. Public health interests would then remain invisible, undervalued and without influence. This means that public health specialists need to understand the importance of the interplay of 
factors that influence boards when taking decisions. They must also be able to exercise the sensitive use of skills such as negotiation, political awareness and strategic thinking.

The North Thames review findings ${ }^{4}$ spurred the development of a prototype programme for public health specialists. The programme offered a choice of communication, team playing, influencing and action skill courses. Participants could also experience the contribution made to health improvement by organisations and individuals outside the NHS, and were given the opportunity to attend advanced management development courses.

If the public health perspective is to be influential, then that influence must not come from the public health specialist alone. There are a number of groups that could promote the public health perspective if better educated in epidemiology, health service evaluation and health promotion. Such groups include clinicians, policy makers, researchers, academics, educationalists, planners and managers.

Health board members are truly influential but need a general awareness of the principles of public health to ensure that the health of the population stays high on the agenda. Politicians need to be convinced that health improvement can only succeed if the principles of public health are endorsed and practised across Government. The international dimension must also be considered and there are lessons to be learned from Europe and further afield. Project Mégapoles, a public health network that was conceived in 1997 by the European Community Action Programme on Health Promotion, Information, Education and Training, is fostering best practice across the cities of Europe.

The project, coordinated by Stockholm County Council, brings together politicians and public health specialists. It seeks effective models for reducing inequalities in health in three priority areas: the socially disadvantaged, the youth and young families, and people over 65 years of age - some of the most vulnerable groups in society. By the end of next year (2001) the project will have encouraged the mutual learning of best practice in health promotion and public health across 12 European cities, with particular emphasis on practical projects at the community level.

In 1997, the Chief Medical Officer's project ${ }^{5}$ was set up to consider how best to strengthen the public health function in England, and some of the issues raised are discussed in the public health white paper. ${ }^{1}$ The project has identified the need for a greater expertise among public health specialists and some funding has been made available to support this need.

Building on the findings of the original North Thames review, ${ }^{4}$ the experience of the prototype health development programme and with funding from the Chief Medical Officer's project, North Thames Region, in conjunction with three partner organisations, have designed a health leadership programme.This modular programme, started in October 1998 and called "Leading for Health", is open to senior people from a range of health disciplines in the NHS and affiliated organisations. The programme, which will run for two years, will focus on the present government's requirements: effective partnership working and the development of communities. A comparison of its effectiveness will take place with a parallel programme undertaken by the National Health Service Executive in the West Midlands Region.

Participants in the North Thames programme will learn about, and be exposed to, processes such as economic and critical appraisal analysis, legal frameworks, conflict management and resolution, networking and personal development. The underlying philosophy is to improve the health of the public: a philosophy at the heart of the government's policy for social justice.

Partners in the development of the programme with North Thames Region are:

(1) The London School of Hygiene and Tropical Medicine (England's School of Public Health)

(2) Ashridge Consulting, part of Ashridge Management College Hertfordshire (Business School)

(3) The National Centre for Communicable Disease Surveillance in Colindale London (part of the Public Health Laboratory Service).

All partner organisations are highly regarded in their field at both national and international level. One aim of the programme is to form a continuing network of alumni, truly multidisciplinary and able to cross organisational divides, so that health improvement has the same level of importance as the management of health service resources in the NHS. Given time, such networks will lead to a greater understanding of the contribution that health improvement makes to the overall well being of people and the economy.

To ensure a general improvement in the health of the population, it will be necessary for those who are not specialists to understand the underlying principles of the population health construct and values. This programme is the start of a process that will recognise health leadership as being inclusive and not exclusive.

The author acknowledges the help of Dr Gillian Schiller, Ms Verity Kemp, Ms Hilary Samson Barry, Dr Fiona Sim, Mr Ron Kerr and partner organisations.

1 Secretary of State for Health. Saving lives: our healthier nation. London: The Stationery Office, 1999.

2 Secretary of State for Health. The new NHS-modern, dependable. London: The Stationery Office, 1997.

3 Secretary of State for Health. A first class service. London: The Stationery Office, 1998.

4 NHSE North Thames. Putting health on everyone's agenda. London: NHS Executive, 1997

5 Chief Medical Officer. Chief Medical Officer's project to strengthen the public health function in England. London: Department of Health, 1998. 